\title{
Individual based simulations of the direct and indirect effects of limpets on a rocky shore Fucus mosaic
}

\author{
Mark P. Johnson ${ }^{1, *}$, Michael T. Burrows ${ }^{2}$, Stephen J. Hawkins ${ }^{1}$ \\ ${ }^{1}$ School of Biological Sciences, Division of Biodiversity and Ecology, University of Southampton, Southampton, \\ SO16 7PX, United Kingdom \\ ${ }^{2}$ Dunstafinage Marine Laboratory, PO Box 3, Oban, Argyll, PA34 4AD, United Kingdom
}

\begin{abstract}
Ecological models that include spatial processes can produce complex patterns in space and time. However, the ecological relevance of such behaviour remains unclear. Previous work has generally focused on systems where the dynamics of simulated species are closely linked. We present a stochastic spatial model for an open system where species are only weakly or indirectly linked. The principal interaction, that limpets reduce the local probability of Fucus recruitment, was defined empirically. Fucus abundance at large scales could be approximated without resorting to a spatially explicit model. However, the behaviour of individual limpets at intermediate densities could alter Fucus abundance and small scale spatiotemporal pattern. By altering small scale pattern in simulations, limpets could also affect the population densities of poorly dispersing species dependent on Fucus cover. Increasing the temporal variability of limpet or Fucus populations at large scales led to correlated dynamics at different spatial scales in simulations. There was little correlation between scales in time series taken from the field. This weak correlation between scales suggests that local effects, such as those associated with individual limpet grazing, are important in the dynamics of a real system. Development and testing of the model are facilitated because predictions apply to clearly definable temporal and spatial scales.
\end{abstract}

KEY WORDS: Intertidal Limpet Fucus Pattern Spatial

\section{INTRODUCTION}

Studies that examine the generation of complex spatiotemporal pattern from simple species interactions represent a fruitful and dynamic area of research (Durrett \& Levin 1994, Molofsky 1994, Bascompte \& Solé 1995). Typically these species interactions are simulated using discrete space and time formulations and the resultant behaviour is examined on lattices of cells. Changes in spatiotemporal pattern associated with different parameter values can involve the emergence of strikingly different classes of large scale behaviour For example, one class of behaviour consists of spiral waves rotating around fixed or slowly moving points

\footnotetext{
•E-mail:m.p.johnson@soton.ac.uk
}

on the lattice (Solé et al. 1992). The different kinds of self-organized spatiotemporal behaviour simulated can theoretically affect the persistence of various unstable species interactions (Hassell et al. 1991). However, there is some doubt as to the ecological relevance of such complex and large scale spatiotemporal patterns (Rohani et al. 1997). Even though the spatiotemporal patterns may not be artifacts of the modelling framework (Sherratt et al. 1997), model behaviour may still be misleading due to the assumptions made about species interactions. Two of the most frequently applied assumptions are an absence of stochastic noise and tight coupling between the dynamics of interacting species (Wilson \& Hassell 1997). There are many ecological systems where adherence to these 2 assumptions may be excessively restrictive. The dynamics of open systems include, by definition. 
greater roles for processes such as externally derived recruitment in comparison to species interactions. For some marine systems there may be no scale at which a traditional highly coupled model is applicable (Roughgarden et al. 1994).

In this paper we examine stochastic spatial simulations of grazer populations in an open system where species are weakly or indirectly linked. The principal interaction, that limpets influence the probability of recruitment but not the persistence of Fucus, was defined empirically. Certain species are dependent on the shelter that canopy algae provide and are therefore indirectly affected by the activities of limpets. Three questions are addressed in this paper: When do the predictions of an individual-based spatial model differ from those of a non-spatial model? How do the mobility and habitat preferences of individual limpets affect the spatiotemporal pattern of algal mosaics? How do the mobility and habitat preferences of individual limpets indirectly affect species dependent on the shelter of canopy algae? We also examined the effects of large scale interannual variability in algal and limpet recruitment on our predictions of spatiotemporal pat. tern.

We modelled the intertidal macroalgal community on smooth horizontal ledges in the Isle of Man (Hartnoll \& Hawkins 1985, reviewed in Hawkins et al. 1992). Cover of the dominant canopy forming algae (Fucus spp.) is patchy in this system at approximately the $1 \mathrm{~m}$ scale (Johnson et al. 1997). Time series observations at the patch scale show considerable multiannual variations in Fucus cover (Hartnoll \& Hawkins 1985). Both the patchy distribution of Fucus and the temporal fluctuations are thought to be driven by the activities of grazing limpets Patella spp. Limpets in the Isle of Man forage over short distances $(0.4 \mathrm{~m}$, Hartnoll \& Wright 1977) during tidal submersion before returning to a home scar for the duration of low tide. Grazing around the home scar removes microscopic algal spores and therefore causes a localized reduction in the chance of Fucus recruiting to the shore. As home scars are not evenly spaced, Fucus patches can become established in areas of low local grazing pressure (Johnson et al. 1997). Once Fucus germlings reach a certain size they are too large to be removed by grazing. Limpets occasionally move to a new home scar. One of the most commonly observed changes of home scar is for a limpet to migrate into a Fucus patch. However, as limpets move to Fucus patches, the spatial pattern of grazing pressure is altered, allowing juvemile Fucus to become established elsewhere on the shore. Eventually a patch decays, exposing the limpet home scars aggregated beneath it. In this manner, the limpets drive a shifting mosaic of differently aged patches (see also Duggins 1983).

\section{MATERIALS AND METHODS}

Spatial model formulation. The grazing pressure around individual home scars was defined using a field map of juvenile Fucus and limpet location (Johnson et al. 1997). A 5 by $5 \mathrm{~m}$ quadrat was marked out during spring 1996 close to the area used for monitoring by Hartnoll \& Hawkins (1985). The site is in an area of smooth carboniferous limestone and slopes gently with no large cracks or boulders. A map of the $25 \mathrm{~m}^{2}$ quadrat was produced by dividing the area into square cells, each with an area of $0.01 \mathrm{~m}^{2}$. Cells were classified as empty or containing Fucus. If the Fucus individuals in a cell were less than $0.1 \mathrm{~m}$ in length and lacked reproductive structure, the cell was classed as juvenile (see Knight \& Parke 1953), Observations at Port St. Mary have confirmed that cells classed as juveniles in one year generally became patches of mature Fucus by the following year. The limpet number in each $0.01 \mathrm{~m}^{2}$ cell was also recorded.

The spatial impact of limpets on the probability of recording a juvenile Fucus cell was described using logistic regression (Sokal \& Rohlf 1995). This involved calculating the total number of limpets at each (Euclidean) distance class from a cell. Starting from the current cell, successively larger distances were used in a multiple regression until addition of the limpets in the next distance class did not significantly affect Fucus recruitment probability (Norusis 1993). The final fitted model was of the form.

$$
P_{e}=\frac{e^{f(L)}}{1+e^{f(L)}}
$$

where

$$
f(L)=\beta_{0}+\sum_{i=0}^{4} \beta_{1+1} L_{i}
$$

$P_{e}$ represents the probability of juvenile Fucus being recorded, $\beta$ values are fitted constants and $L_{0}$ to $L_{4}$ are the number of limpets in all cells at distance classes from 0 to 4 cells. Model parameters are given in Table 1 . The grazing impact of limpets decreased with distance from their home scar.

We investigated the spatiotemporal dynamics of the interaction between limpet home scar position and Fucus recruitment probability using a stochastic 'lattice gas' model. Lattice gas models are a class of cellular automata based on discrete particles moving on a spatial grid in discrete time steps (Ermentrout \& Edelstein-Keshet 1993). In this case the particles are limpets and their location represents the position of the home scar Each time step there was a small probability that a limpet would leave its home scar and move to a new location. The grazing pressure exerted by each limpet extended into cells adjacent to the home scar. 
Table 1. Parameters values for logistic regression (Eq. 1) relating Fucus escape probability at any single location to the local density of limpets Patella spp. (Likelihood ratio for addition of next distance class $\left(L_{5}\right)=3.218$ (df 1 ), no significant improvement in fit. Overall goodness of fit $=888.315$ (df 894), error of fit not significant]

\begin{tabular}{|lrrr|}
\hline Parameter & Value & SE & \multicolumn{1}{c|}{$p$} \\
\hline$\beta_{0}$ & 0.7336 & 0.1733 & $<0.001$ \\
$\beta_{1}$ & -0.5386 & 0.1929 & 0.005 \\
$\beta_{2}$ & -0.1926 & 0.0512 & $<0.001$ \\
$\beta_{3}$ & -0.1687 & 0.0449 & $<0.001$ \\
$\beta_{4}$ & -0.1010 & 0.0368 & 0.006 \\
$\beta_{5}$ & -0.0532 & 0.0226 & 0.019 \\
\hline
\end{tabular}

viduals change home scars, how far they move to find a new home scar and whether there is any habitat preference in the choice of a new home scar. These different aspects of limpet behaviour can be summarized as home scar preference, home scar search range and limpet vagrancy. There is little information on the relevant parameter values to use for these processes. Hence many different simulations were run across the range of possible parameter values (Table 2). The probability of a limpet leaving its current location each time step represented the degree of individual vagrancy. This vagrancy can also be thought of as analogous to mortality: a limpet in one location dies and is replaced elsewhere on the grid. When a limpet
The probability of juvenile Fucus occurring in each cell was defined using the logistic regression outlined above.

A. 50 by 50 grid was used to simulate the limpet and Fucus mosaic at a scale equivalent to the spatially referenced data gathered in the field. Hence each cell in simulations was equivalent to $0.01 \mathrm{~m}^{2}$ on the shore. Periodic boundary conditions were used so that a limpet moving off one side of the grid reappeared at a location on the opposite edge. At the start of each simulation, a fixed number of limpets were allocated to randomly chosen cells on the grid. Each subsequent time step involved redistribution of limpets, followed by the generation of Fucus escapes dependent on the spatial pattern of grazing pressure and then aging of the existing Fucus occupied cells (Fig. 1), Each time step was intended to be equivalent to a year on the shore. Fucus.was assumed to persist in individual cells for 5 time steps. This is derived from the 5 yr cycle length given for experimentally created Fucus escapes at Port St. Mary by Southward (1956).

Limpet behaviour at the simulation time step of 1 yr does not reflect individual foraging excursions from the home scar. The impact of all individual foraging excursions over the course of a year is integrated into the field estimate of the average grazing effect in Eq. (1). At the annual timescale the limpet behaviour of importance relates to how often indi-

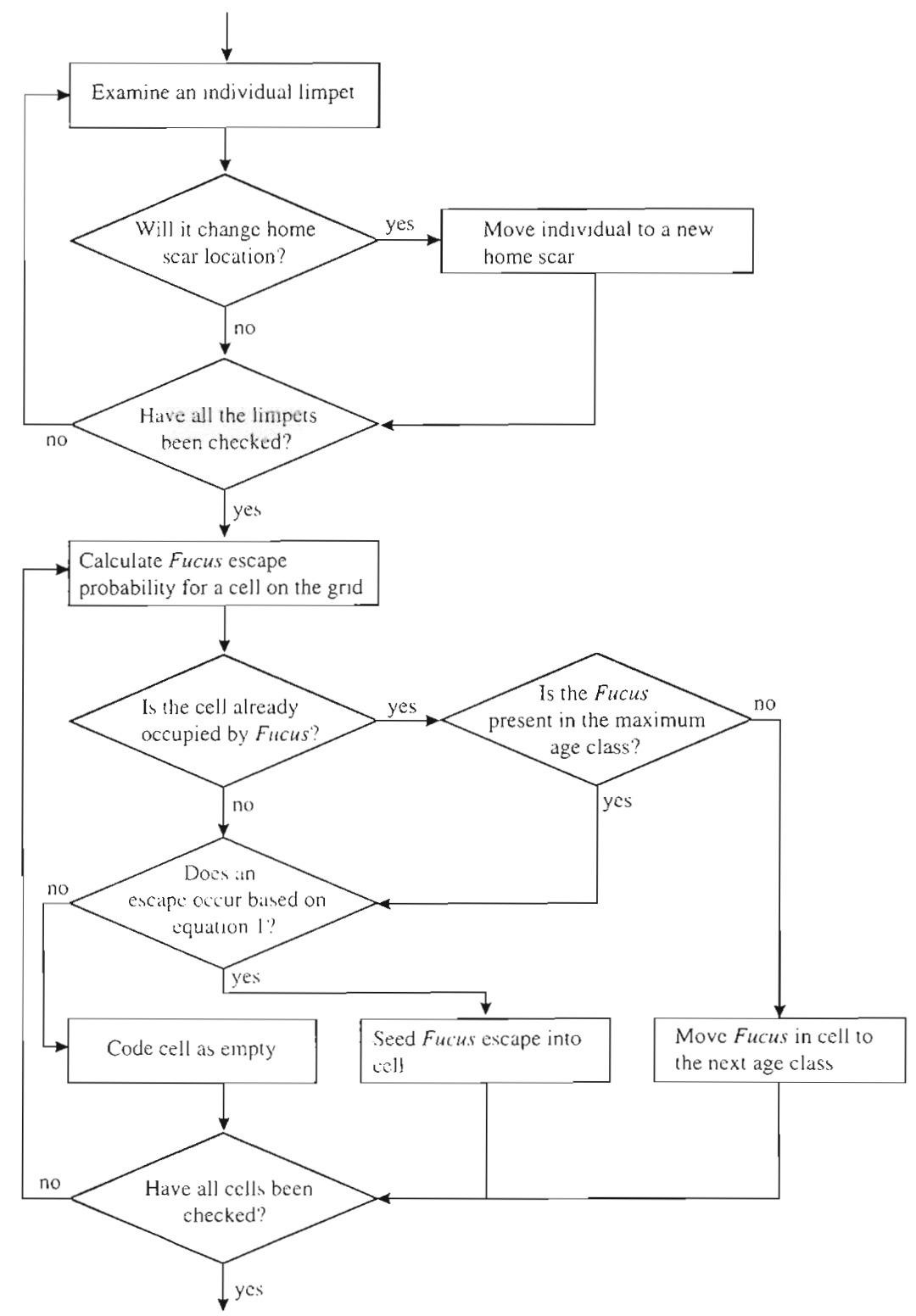

Fig. 1 Flow diagram for a single time step of the limpet - Fucus spatiotemporal model 
Table 2. Parameter ranges used to describe limpet behavıour. Parameter values were fixed within each 500 time step simulation, but varied between separate simulations. For full details of usage see text

\begin{tabular}{|c|c|c|c|}
\hline Parameter name & Usage & Minimum & Maximum \\
\hline Home scar search range & Maximum distance from current to new home scar & 1 & 25 \\
\hline Vagrancy & Probability of leaving home scar per time step & 0 & 1 \\
\hline Fucus preference & Probability of accepting a cell containing Fucus & 0 & 1 \\
\hline Limpet preference & Probability of accepting a cell containing limpets & 0 & 1 \\
\hline
\end{tabular}

changed home scar, a new site was selected at random from all the cells within a certain distance of the old home scar (the search range). Home scar preference was expressed by altering the probability for accepting a new location dependent on whether that location already contained Fucus or other limpets. For example, a location without Fucus present could be rejected with a probability of 0.8 , while a location with limpets already present could be accepted with a probability of 0.9 . These probabilities were independent. If a location was not accepted, iterations continued until a site was picked.

Patches of mature Fucus represent a resource to organisms such as understory algae, anemones (Actinia spp.), encrusting epifauna, and molluscs [e.g. Nucella lapilus (L.) and Littorina spp.] which would otherwise be rare on smooth rock platforms (Thompson et al. 1996). If species have no planktonic larval stage and limited adult dispersal ability, for example N. lapilus and Littorina obtusata (L.), the spatial and temporal pattern of Fucus may become important for their persistence on the shore. The population dynamics of such canopy dependent species were simulated using a simple cell occupancy algorithm. Following a random seeding of individuals into a quarter of all cells on the grid, survival at each location was dependent on the cell also containing Fucus. Each unoccupied cell adjacent to an occupied cell ( 8 cell neighbourhood) was recoded as occupied with a fixed probability per time step.

A non-spatial equivalent of the limpet - Fucus model outlined above can be constructed by assuming that limpets are present at an average density in every spatial location. Changes in Fucus cover are therefore given by:

$$
\frac{\mathrm{d} F}{\mathrm{~d} t}=P_{e}(s-F)-x F
$$

where $P_{e}$ is the probability of Fucus recruitment as defined by Eq. (1), $F$ is the number of cells occupied by Fucus, $s$ is the total number of sites available for Fucus and $x$ is the algal mortality rate $(0.2$ per time step for $a$ 5 yr life span). The equilibrium is given by:

$$
\hat{F}=\frac{s}{1+\frac{x}{P_{e}}}
$$

Most simulations were run with fixed densities of limpets and set background recruitment probabilities for Fucus. There is some evidence that the densities of Fucus and limpets converge to site-specific steady states even after large disturbances such as oil spills (Southward \& Southward 1978). Hence the assumptions of temporally invariable recruitment probabilities may not be too restrictive (see also Åberg \& Pavia 1997). To examine the potential effect of fluctuating limpet and Fucus densities, simulations were carried out with grid scale limpet numbers and Fucus recruitment varying at random from one time step to the next.

Analysis of spatiotemporal pattern in simulations. Temporal variability in the number of cells occupied by Fucus was investigated at 2 spatial scales: over the entire 2500 cell grid and in a fixed area of 10 by 10 cells, which approximates the estimated patch scale in the natural system (Johnson et al. 1997). Cell occupancy totals in simulations generally converged to their long term pattern after about 10 time steps. Hence variability at the patch scale was estimated from 500 time step simulations with the first 50 values discarded. The average coefficient of variation from all the available 20 time step 'windows' was used as a measure of short term temporal variability. This measure was chosen as it provided a univariate method of distinguishing between time series with the same degree of temporal autocorrelation but with different amplitudes of fluctuation.

The spatial pattern in simulations was investigated using the number of times that pairs of cells at specific distances were recorded as both containing Fucus (join counts, Sokal \& Oden 1978, Upton \& Fingleton 1985). The neighbourhood for each cell included all orthogonal and diagonal connections at a specific distance. Patch structure on the lattice causes there to be more pairs of Fucus-occupied cells at short distances than would be expected if the spatial pattern was random. The range of cells over which there are significantly more join counts than would be expected provides an 
estimate of the scale of aggregation on the lattice. Spatial pattern in separate time series was summarized using the geometric mean of the number of cells over which there was significant spatial autocorrelation. This pattern measure is strongly correlated with various other autocorrelation measures but has the advantage of giving an instantly recognizable range of cells when compared to more abstract formulations such as the 'clumping index' (Hendry \& McGlade 1995).

\section{RESULTS}

Increasing the density of limpets reduced the average Fucus abundance in simulations. However, the abundance of Fucus at a scale equivalent to $25 \mathrm{~m}^{2}$ on the shore was relatively insensitive to changes in parameters affecting limpet behaviour. The effects of changing the limpet density in spatially explicit simulations could be approximated using non-spatial models (Fig. 2). At low and high limpet densities there was little spatial aggregation of Fucus-occupied cells in simulations. However, at densities between approximately 0.16 and 0.88 limpets cell ${ }^{-1}$ there was significant spatial autocorrelation, even when limpets chose new home scar locations at random. Effects associated with different limpet behaviours and differences between spatial and non-spatial models were always most apparent at intermediate limpet densities (Fig. 3). For example, a rise in the level of individual vagrancy so that limpets changed home scar every time step, instead of once every 10 time steps on average,

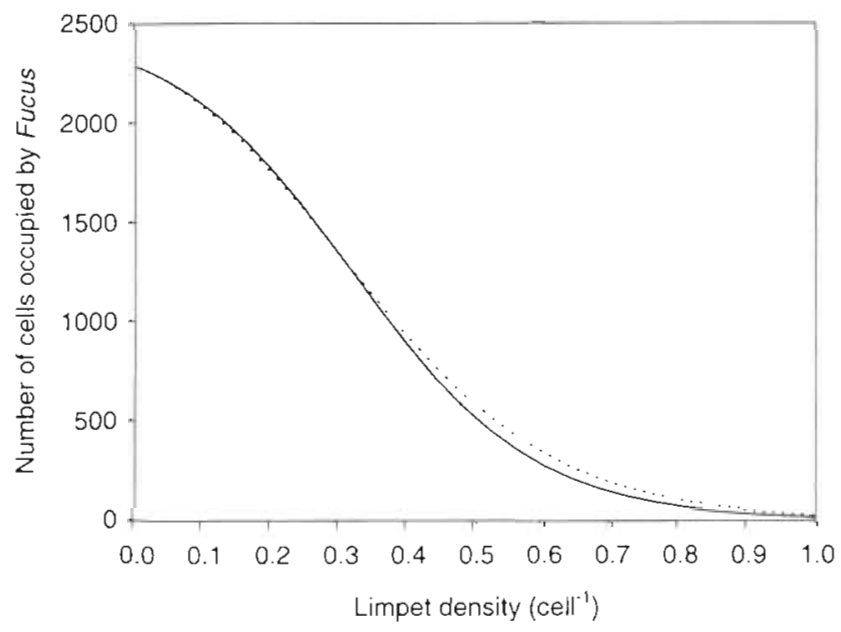

Fig. 2. Relationships between the average number of grid cells occupied by mature Fucus and limpet density. The average abundances in simulations are given by the dotted line predictions from the equilibria of a non-spatial model are given by the solid line. In the simulation, limpets moved once every 10 time steps on average, with a search range of 6 cells and no preference for any particular home scar type
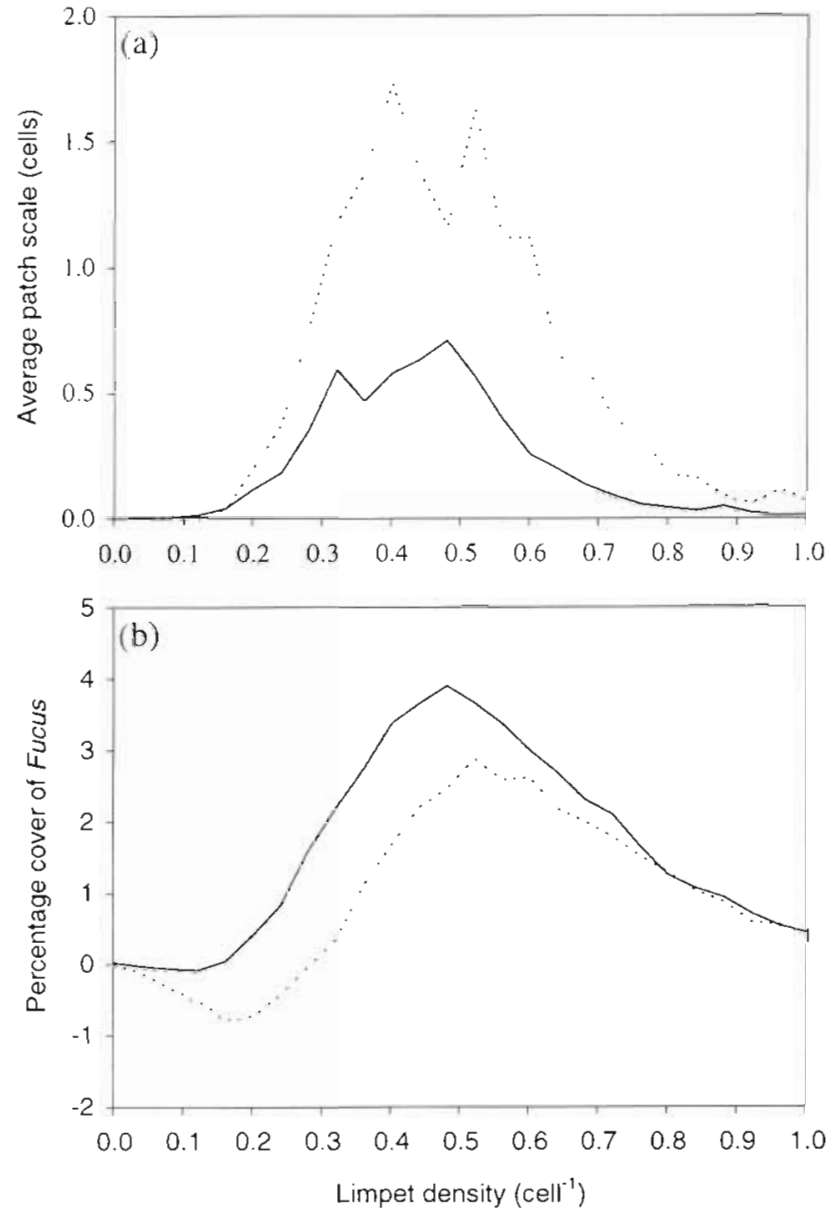

Fig. 3. (a) Average extent of spatial autocorrelation in simulations with different densities of limpets; (b) differences in Fucus percentage cover between the non-spatial model and individual-based simulations. In simulations different individuals had no preference for any particular home scar type and changed location every time step (solid line) or once every 10 time steps on average (dotted line)

decreased the degree of spatial autocorrelation and increased the average number of Fucus-occupied grid cells when there were intermediate numbers of limpets.

We investigated the role of limpet behaviour in simulations with 800 individuals $\left(0.32 \mathrm{cell}^{-1}\right)$. This density not only emphasized the changes caused by different parameter values, it is also representative of field counts on moderately exposed shores in the Isle of Man. In counts from different $25 \mathrm{~m}^{2}$ quadrats there were between 201 and 959 individuals (equivalent to 0.08 and 0.38 limpets cell ${ }^{-1}, n=10$ ).

Limpet mobility on the grid was dependent on 2 parameters: individual vagrancy and home scar search range. Increasing individual mobility always increased the proportion of grid cells occupied by Fucus (Table 3). Highly mobile limpets reduced the extent of 

erences on overall Fucus abundance and spatiotemporal pattern in simulations. For (a), limpets had no preference for any particular home scar type. For (b), home scar range in simulations was held at 6 cells, with individuals changing home scar once every 10 time steps on average. total = average total abundance of Fucus on lattice; patch = average patch scale; variability = short term temporal variability of Fucus cover at the patch scale; vagrancy = probability of an individual changing home scar each time step; $h s r=$ home scar search range; $P(F)=$ probability of accepting a cell occupied by Fucus, independent of the presence of limpets; $P(L)=$ probability of accepting a cell occupied by limpets, independent of the presence of Fucus. Regressions were fitted by forward stepwise selection; all independent variables included significantly affected the fit; $\mathrm{n}=$ number of simulations used to derive relationships

\begin{tabular}{|lccc|}
\hline Fitted equation & $\mathrm{n}$ & $\mathrm{r}^{2}(\%)$ & $\mathrm{p}$ \\
\hline (a) Limpet mobility & & & \\
total $=1222.16+51.78$ vagrancy $+1.061 \mathrm{hs}$ & 70 & 83.6 & $<0.001$ \\
patch $=1.04-0.36$ vagrancy $-0.01 \mathrm{hsr}$ & 70 & 31.0 & $<0.001$ \\
variability $=10.93+1.80$ vagrancy $+0.053 \mathrm{hsr}$ & 70 & 36.7 & $<0.001$ \\
(b) Habitat preferences & & & \\
total $=1284.4-121.6 P(F)+1.22 .3 P(L)$ & 73 & 54.8 & $<0.001$ \\
patch $=4.2-5.1 P(F)+1.9 P(L)$ & 73 & 82.1 & $<0.001$ \\
variability $=10.5+1.7 P(F)-1.7 P(L)$ & 73 & 21.0 & $<0.001$ \\
& & & \\
\hline
\end{tabular}

Table 3. Relationships between (a) limpet mobility and (b) habitat pref-

This dataset was based on a large number of simulations within a small range of Fucus and canopy dependent species abundance, associated with a limpet density of $0.32 \mathrm{cell}^{-1}$ and a colonization probability of 0.25 per time step. Between 43 and $54 \%$ of the grid cells contained Fucus at this limpet density. This procedure removed positive correlations in the data set between the abundance of Fucus and the density of canopy dependent species. The mean patch scale and short term variability in the data set were also not correlated and can therefore be considered independent. Average population densities of canopy dependent species were highest in simulations where limpet behaviour produced a temporally stable and spatially aggregated Fucus mosaic (Table 4). Such conditions reflect an increased probability that a cell containing a canopy dependent species will be adjacent to a cell available for colonization, and a reduced probability that a patch of Fucus-occupied cells will decay to become unoccupied. Stable and patchy spatiotemporal pattern would be associated with limpets spatial aggregation and increased short term variability at the patch scale. Preferences in the choice of new home scar locations affected the grid scale abundance, spatial aggregation and short term variability of Fucusoccupied cells in simulations (Table 3). The grid scale abundance was increased when limpets were more likely to move to locations already occupied by limpets while simultaneously avoiding Fucus. This behaviour also increased the extent of spatial autocorrelation in simulations. Conversely, if limpets were more likely to move into Fucus-occupied cells and away from each other, the patch scale temporal variability increased.

In simulations with 0.32 limpets cell ${ }^{-1}$ there was a threshold colonization probability for canopy dependent species. Dependent species could not persist in simulations when the colonization probability was below a certain value. However, the value of the threshold colonization probability depended on the spatiotemporal pattern of the Fucus mosaic, as influenced by assumptions about limpet behaviour (Fig. 4).

The population density of canopy dependent species above the extinction threshold was related to the overall abundance of Fucus-occupied cells as well as the colonization probability. The potential parameter space in simulations was therefore extensive. The relationships between the spatiotemporal pattern produced by limpet behaviour and the abundance of canopy dependent species were consequently investigated in an intensive data set where there was no covariation between Fucus and dependent species. that were not vagrant, did not have a high home scar search range, were unlikely to choose cells occupied

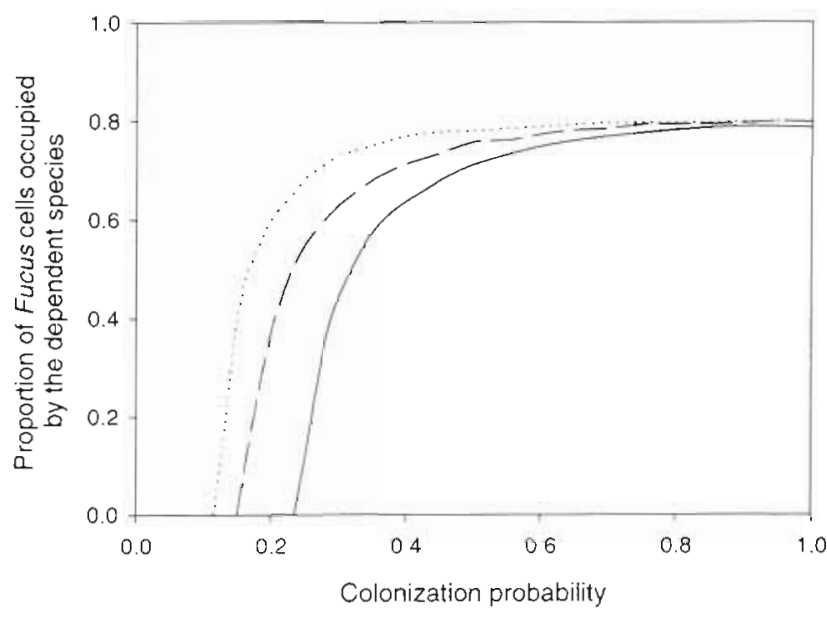

Fig. 4. Changes in the average proportion of Fucus cells occupied with different colonization probabilities for a canopy dependent species. Simulations had the equivalent of 0.32 limpets cell ${ }^{-1}$. The solid line is from simulations where limpets had a home scar search range of 6 , a vagrancy of 0.1 , a probability of accepting Fucus-containing cells of 0.95 and a probability of accepting limpet=containing cells of 0.05 . Parameters for the dotted line were identical except the habitat preferences were switched to a probability of accepting Fucus-containing cells of 0.05 and a probability of accepting limpet-containing cells of 0.95 . The dashed line shows results from simulations where cells were randomly seeded with Fucus and hence there was no spatial structure 
Table 4. Dependence of the average population size of canopy dependent species on the degree of spatial autocorrelation and short term temporal variability at the patch scale in simulations. dependents $=$ the average number of cells containing canopy dependent species in simulations; patch = average patch scale $;$ variability = short term temporal variability of Fucus cover at the patch scale. Regression was fitted by forward stepwise selection; all independent variables included significantly affected the fit; total number of simulation runs $=136$

\begin{tabular}{|lcc|}
\hline Fitted equation & $\mathrm{r}^{2}(\%)$ & $\mathrm{p}$ \\
\hline dependents $=433.5+69.1$ patch -28.0 variability & 70.5 & $<0.001$ \\
\hline
\end{tabular}

by Fucus and more likely to move to cells occupied by conspecifics.

When the interannual recruitment variability is low, the chance of Fucus recruiting to any cell on the simulation grid is dependent on the modification of the background Fucus recruitment level by the local limpet density. Each time step a range of cell specific recruitment probabilities are produced, dependent on the spatial distribution of limpets. However, if Fucus recruitment or limpet densities are highly variable from year to year, the interannual range of Fucus recruitment probabilities may be greater than the range of local probabilities due to the spatial arrangement of limpets. Under such conditions, the Fucus recruitment probability for any single cell can be approximated using a combination of overall number of limpets and the background recruitment probability of Fucus. When grid scale averages can be used to estimate the recruitment probability for any single cell, position on the grid becomes unimportant and the dynamics of all cells become correlated. Hence the dynamics of small and large scale Fucus abundances become correlated as recruitment becomes more variable from year to year (Fig. 5). The same result can be demonstrated with increasing interannual variation in limpet density.

\section{DISCUSSION}

\section{Relevance of simulated spatial patterns}

We have demonstrated that a simple formulation for the local effect of limpets on Fucus recruitment produces a variety of effects in stochastic spatial simulations. Changes in spatiotemporal pattern associated with changes in limpet behaviour were emphasized at intermediate limpet densities. Effects on spatiotemporal pattern were produced without assuming that the system contained species described by tightly coupled and deterministic equations. Large scale complex behaviour, such as spiral waves, did not emerge in sim- ulations. However, the different patterns produced were sufficient to suggest that limpet behaviour can alter the structure of Fucus mosaics and hence the persistence of canopy dependent species. We can address 2 questions about the ecological relevance of the simulated patterns. Firstly, does the simulated behaviour of limpets reflect the actual variation of limpet behaviour in the field? More generally, do the temporal fluctuations reported in Hartnoll \& Hawkins (1985) actually represent recruitment variability occurring at the scale of limpet grazing effects?

Phenomena such as individual vagrancy, home scar search range and home scar preference do actually reflect what is known about limpet behaviour in the field. Limpet vagrancy is thought to be affected by the smoothness of the rock surface (Jones 1948). Alternatively, the probability of leaving a home scar can be thought of as analogous to population turnover. A. high individual vagrancy would represent a case where an individual's mortality risk was large but the population was stable due to replacement elsewhere. Limpet habitat preference hierarchies also change. In the quadrat at Port St. Mary used to define the local grazing effects, limpets were distributed in a pattern that reflected probabilities of 0.7 for moving to both a limpet-and a Fucus-occupied cell. Other species of limpets avoid conspecifics, leading to a uniform spacing on the shore (Mackay \& Underwood 1977). It is likely that, even on the same shore, the preference hierarchy of Patella spp. will change in response to environmental gradients. For example, desiccation

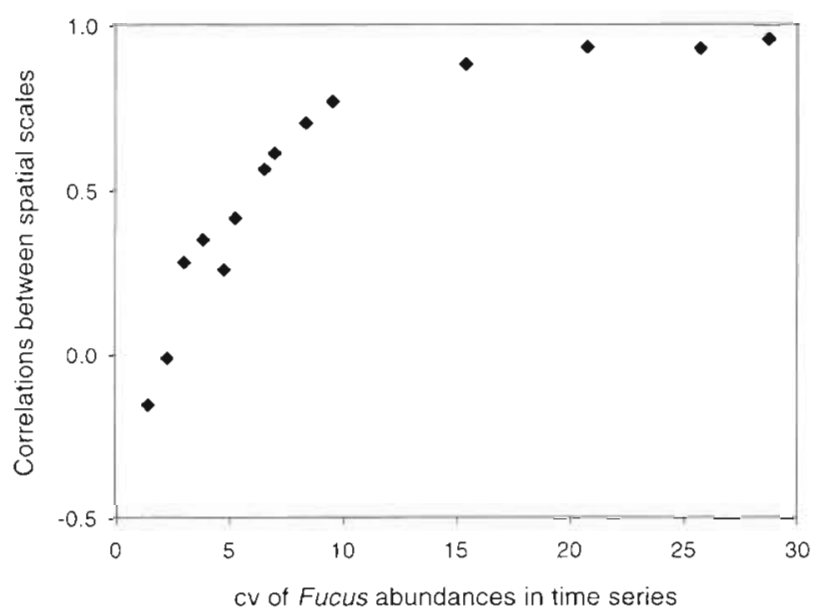

Fig. 5. Nonparametric correlations in time series between a fixed 100 cell window and the rest of the simulation grid with increasing variability in grid scale Fucus abundance caused by interannual recruitment variability. cv: coefficient of variation 
stress may affect the habitat preferences of limpets found high on the shore.

Interannual recruitment variability can be associated with weather conditions. For example, a good year for Fucus may lead to the presence of germlings across an entire shore (cf. Gunnill 1980, Lively et al. 1993). The results demonstrated that when recruitment is dominated by large scale processes instead of localized grazing effects, the Fucus cover in separate small areas is not independent. Under these circumstances, there is a strong temporal autocorrelation between Fucus cover at the patch scale and at the larger scale where recruitment variability acts. We can test for the degree of autocorrelation between scales at Port St. Mary because the time series records reported for a $2 \mathrm{~m}^{2}$ quadrat in Hartnoll \& Hawkins (1985) are accompanied by a series of broad scale shore photographs. Each broad scale photograph was taken in a fixed location every year and covered an area of approximately $2500 \mathrm{~m}^{2}$. Observers were asked to rank the Fucus cover in photographs on a scale of 1 to 10 . Separate observers tended to agree on the relative ranks of different photographs (minimum nonparametric correlation between pairs of observers $=0.817, p<0.001$, with 7 observers and 30 different photographs). However, there was no significant correlation between the broad scale photographs and small scale quadrat records from the same area (nonparametric correlation $=0.237$, $p=0.510, n=10)$. This implies that recruitment variability at Port St. Mary was structured more by local processes than by whole shore processes. Although the role of limpets has been demonstrated in the field, it is worth emphasizing that there may be other small scale processes additionally affecting Fucus abundance. For example, processes such as patchy Fucus recruitment in the absence of limpets remain to be investigated (Johnson et al. 1997). A further point is that this study concentrated on the mid shore at Port St. Mary, an area where limpet effects on Fucus recruitment have been demonstrated repeatedly (Jones 1948, Lodge 1948. Southward 1956, Hawkins 1981, Johnson et al. 1997). It would be interesting to expand this approach to other areas where the number and strengths of species interactions may be different.

In the Fucus mosaic model originally proposed by Hartnoll \& Hawkins (1985), the presence of barnacles enhanced Fucus recruitment. As such, the effects of barnacles can be considered implicitly in simulations by altering the probability for escapes occurring on the shore. Barnacle settlement is known to be very variable from year to year (Hawkins \& Hartnoll 1982). Hence a consequence of including barnacles would be an increase in Fucus recruitment variability. However, results from the correlation across spatial scales presented above imply that interannual variability in bar- nacle recruitment was not an important factor in small scale Fucus abundance.

Alterations in the spatial and temporal patterns expressed by a Fucus mosaic will result in changes in the community dependent on Fucus clumps alongside the indirect effects on single species. At a patch scale, increased temporal variability will favour opportunist species (cf. Sousa 1979). The turnover rate of clumps can be considered as a disturbance frequency. There may be some intermediate patch turnover rate which maximizes the number of species associated with Fucus clumps (Connell 1978). However, the epifauna associated with marine algae may form competitive networks rather than strict hierarchies (Seed \& O'Connor 1981). In this case species richness would rise with decreasing patch turnover.

\section{Models of spatiotemporal patterns}

Models that consider spatial effects in ecology generally fall into one of 2 traditions. One approach emphasizes spatially explicit forms of equations derived from classical population dynamics to investigate whether model predictions are altered and how pattern can be generated from biology in homogenous landscapes (Rohani et al. 1997). In comparison, the landscape ecology tradition tends to consider how species respond to particular predetermined spatial (With \& King 1997) or spatiotemporal patterns (Moloney \& Levin 1996). The model that we developed represents something of a hybrid between these traditions. Spatiotemporal pattern was generated in a homogenous landscape by an interaction between limpets and Fucus. Although complex large scale patterns were not evident, ecologically relevant spatial and temporal effects were produced in a stochastic model that did not depend on tightly coupled and closed populations. The spatiotemporal pattern of Fucus represented a landscape mosaic to the canopy dependent species. At a density of 0.32 limpets cell ${ }^{-1}$ there were not enough Fucus cells for the entire mosaic to be interconnected. Hence canopy dependent species with a colonization probability of 0.25 were not able to move freely into all the Fucus cells on the grid. In Iandscape ecology terms the Fucus density was below the percolation threshold (commonly around $60 \%$ of cells occupied; Wiens et al. 1997). Results in this study are similar to those previously reported in landscape ecology studies, in that the spatiotemporal pattern of Fucus had significant effects on the densities of canopy dependent species when Fucus densities were below the percolation threshold (e.g. Adler \& Nuerberger 1994).

We believe that studies of this type represent an important link between theory and data regarding the 
role of spatial interactions in ecology. Much of the spatially explicit theory developed remains essentially 'scale free'. This is despite the well-recognized danger of extrapolation between scales (Wiens 1989). Even where scaling methods are used in lattice models (e.g. Rand \& Wilson 1995), applications to real systems can be problematical as the time and space scales are defined internally. If the characteristic length scale of a lattice model is 10 by 10 cells, use of this information is limited by the fact that cell size and time step for the model have probably not been defined in concrete units. By empirically defining our principal interaction, we were able to consider data from different sources and confirm the importance of patch scale processes. The model presented here produces output that can be interpreted in terms of real time and space scales. Hence it is easier to design future experiments and observations than would be the case if our scales were abstract.

Acknowledgements. We thank the Natural Environmental Research Council for funding via grant no. GST/02/983 and the volunteers from the MAST Advanced Study Course in Port Erin for scoring Fucus abundance in photographs. S.J.H. received additional support from the EU under MAST program contract MAS3-CT95-0012 (EUROROCK).

\section{LITERATURE CITED}

Åberg PA, Pavia H (1997) Temporal and multiple scale variation in juvenile and adult abundance of the brown alga Ascophyllum nodosum. Mar Ecol Prog Ser 158: 111-119

Adler FR, Nuernberger B (1994) Persistence in patchy irregular landscapes. Theor Popul Biol 45:41-75

Bascompte J, Solé R (1995) Rethinking complexity: modelling spatiotemporal dynamics in ecology. Trends Ecol Evol 10: $361-366$

Connell JH (1978) Diversity in tropical rain forests and coral reefs. Science 199:1302-1310

Duggins DO (1983) Starfish predation and the creation of mosaic patterns in a kelp-dominated community. Ecology $64: 1610-1619$

Durrett R, Levin SA (1994) Stochastic spatial models: a user's guide to ecological applications. Phil Trans R Soc Lond B $343: 329-350$

Ermentrout GB, Edelstein-Keshet L (1993) Cellular automata approaches to biological modelling. J Theor Biol 160 . $97-133$

Gunnill FC (1980) Recruitment and standing stocks in populations of one green alga and five brown algae in the intertidal zone near La Jolla, California during 1973-1977. Mar Ecol Prog Ser 3:231-243

Hartnoll RG, Hawkins SJ (1985) Patchiness and fluctuations on moderately exposed rocky shores. Ophelia 24:53-63

Hartnoll RG, Wright JR (1977) Foraging movements and homing in the limpet Patella vulgata L. Anim Behav 25: $806-810$

Hassell MP, Comins HN, May RM (1991) Spatial structure and chaos in insect population dynamics. Nature 353:255-258

Hawkins SJ (1981) The influence of season and barnacles on algal colonisation of Patella vulgata L. exclusion areas. J Mar Biol Assoc UK 61:1-15

Hawkins SJ, Hartnoll RG (1982) Settlement patterns of Semibalanus balanoides (L.) in the Isle of Man (1977-1981). $J$ Exp Mar Biol Ecol 62:271-283

Hawkins SJ, Hartnoll RG, Kain (Jones) JM, Norton TA (1992) Plant-animal interactions on hard substrata in the northeast Atlantic. In: John DM, Hawkins SJ, Price JH (eds) Plant-animal interactions in the marine benthos. Systematics Association Special Volume No. 46. Clarendon Press, Oxford, p 1-32

Hendry RJ. McGlade JM (1995) The role of memory in ecological systems. Phil Trans R Soc Lond B 259:153-159

Johnson MP, Burrows MT, Hartnoll RG. Hawkins SJ (1997) Spatial structure on moderately exposed rocky shores: patch scales and the interactions between limpets and algae. Mar Ecol Prog Ser 160:209-215

Jones NS (1948) Observations and experiments on the biology of Patella vulgata at Port St. Mary, Isle of Man. Proc Trans Liv Biol Soc 56:60-77

Knight M, Parke M (1953) A biological study of Fucus vesiculosus L. and F. serratus L. J Mar Biol Assoc UK 29:439-514

Lively CM, Raimondi PT, Delph LF (1993) Intertidal community structure: space-time interactions in the Northern Gulf of California. Ecology 74:162-173

Lodge SM (1948) Algal growth in the absence of Patella on an experimental strip of foreshore, Port St. Mary, Isle of Man. Proc Trans Liv Biol Soc 56:78-83

Mackay DA, Underwood AJ (1977) Experimental studies on homing in the intertidal patellid limpet Cellana tramoserica (Sowerby). Oecologia 30:215-237

Molofsky J (1994) Population dynamics and pattern formation in theoretical populations. Ecology 75:30-39

Moloney KA, Levin SA (1996) The effects of disturbance architecture on landscape-level population dynamics Ecology 77:375-394

Norusis MJ (1993) SPSS for windows: advanced statistics release 6.0. SPSS Inc, Chicago

Rand DA, Wilson HB (1995) Using spatio-temporal chaos and intermediate-scale determinism to quantify spatially extended ecosystems. Proc R Soc Lond B 259:111-117

Rohani P, Lewis TJ, Grünbaum D, Ruxton GD (1997) Spatial self-organization in ecology: pretfy patterns or robust reality? Trends Ecol Evol 12:70-74

Roughgarden J, Pennington T, Alexander S (1994) Dynamics of the rocky intertidal zone with remarks on generalization in ecology. Phil Trans R Soc Lond B 343:79-85

Seed R, O'Connor RJ (1981) Community organization in marine algal epifaunas. Annu Rev Ecol Syst 12:47-94

Sherratt JA, Eagan BT, Lewis MA (1997) Oscillations and chaos behind predator-prey invasion: mathematical artifact or ecological reality? Phil Trans R Soc Lond B 352: $21-38$

Sokal RR, Oden NL (1978) Spatial autocorrelation in biology 1. Methodology. Biol J Linn Soc 10:199-228

Sokal RR, Rohlf FJ (1995) Biometry, 3rd edn. WH Freeman and Company, New York

Solé RV, Valls J, Bascompte J (1992) Spiral waves, chaos and multiple attractors in lattice models of interacting populations. Phys Lett A 166:123-128

Sousa WP (1979) Disturbance in marine intertidal boulder fields: the nonequilibrium maintenance of species diversity. Ecology 60:1225-1239

Southward AJ (1956) The population balance between limpets and seaweeds on wave beaten rocky shores. Annu Rep Mar Biol Stat Port Erin 68:20-29

Southward AJ, Southward EC (1978) Recolonization of rocky 
shores in Cornwall after use of toxic dispersants to clean up the Torrey Canyon spill. J Fish Res Board Can 35: $682-706$

Thompson RC, Wilson BJ, Tobin ML, Hill AS, Hawkins SJ (1996) Biologically generated habitat provision and diversity of rocky shore organisms at a hierarchy of spatial scales. J Exp Mar Biol Ecol 202:73-84

Upton GJG, Fingleton B (1985) Spatial data analysis by example, Vol 1. Point pattern and quantitative data. John Wiley and Sons, Chichester

Editorial responsibility: Otto Kinne (Editor), Oldendorf/Luhe, Germany
Wiens JA (1989) Spatial scaling in ecology. Funct Ecol 3: $385-397$

Wiens JA, Schooley, RL, Weeks RD Jr (1997) Patchy landscapes and animal movements: do beetles percolate? Oikos 78:257-264

Wilson HB, Hassell MP (1997) Host-parasitoid spatial models: the interplay of demographic stochasticity and dynamics. Proc R Soc Lond B 264:1189-1195

With KA, King AW (1997) The use and misuse of neutral landscape models in ecology. Oikos 79:219-229

Submitted: March 11, 1998; Accepted: May 26, 1998

Proofs received from author(s): July 3, 1998 